\title{
CANOPY LEVEL CHLOROPHYLL FLUORESCENCE AND THE PRI IN A CORNFIELD
}

\author{
Elizabeth M. Middleton ${ }^{a}$, Yen-Ben Cheng ${ }^{b}$, Lawrence A. Corp ${ }^{c}$, Petya K.E. Campbell ${ }^{d}$, \\ K. Fred Huemmrich ${ }^{d}$, Qingyuan Zhang ${ }^{e}$, and William P. Kustas ${ }^{f}$ \\ a Biospheric Sciences Laboratory, NASA/ Goddard Space Flight Center (GSFC), \\ Greenbelt, MD 20771, USA \\ ${ }^{\mathrm{b}}$ Earth Resources Technology, Inc. (ERT), Laurel, MD 20707, USA \\ ${ }^{\mathrm{c}}$ Sigma Space Corp, Lanham, MD 20706, USA \\ ${ }^{\mathrm{d}}$ Joint Center for Earth Technology/Univ. Maryland Baltimore Co. (JCET/UMBC), \\ Baltimore, MD 21228, USA \\ ${ }^{\mathrm{e}}$ Universities Space Research Association (USRA), Columbia, MD 21044, USA \\ ${ }^{\mathrm{f}}$ Hydrology and Remote Sensing Laboratory, USDA/ARS, Beltsville, MD 20705, USA \\ *Corresponding author, email: Elizabeth.M.Middleton@ nasa.gov
}

\begin{abstract}
Two bio-indicators, the Photochemical Reflectance Index (PRI) and solar-induced red and far-red Chlorophyll Fluorescence (SIF), were derived from directional hyperspectral observations and studied in a cornfield on two contrasting days in the growing season. Both red and far-red SIF exhibited higher values on the day when the canopy in the early senescent stage, but only the far-red SIF showed sensitivity to viewing geometry. Consequently, the red/farred SIF ratio varied greatly among azimuth positions while the largest values were obtained for the "hotspot" at both growth stages. This ratio was lower $(\sim 0.88 \pm 0.4)$ in early July than in August when the ratio approached equivalence (near $\sim 1$ ). In concert, the PRI exhibited stronger responses to both zenith and azimuth angles and different values on the two growth stages. The potential of using these indices to monitor photosynthetic activities needs further investigation.
\end{abstract}

Index Terms - Ecosystems, agriculture, hyperspectral sensors, photosynthesis

\section{INTRODUCTION}

Determining the health and vigor of vegetation using high spectral resolution remote sensing techniques is a critical component in monitoring productivity from both natural and managed ecosystems and their feedbacks to climate [1]. Two spectrally based indices now used in field studies to assess whether vegetation is performing near-optimally or exhibiting symptoms of environmental stress (e.g., drought or nutrient deficiency, non-optimal temperatures, etc.) are the Photochemical Reflectance Index (PRI) [2] and solarinduced red and far-red Chlorophyll Fluorescence (SIF)[35]. Both the PRI and SIF express the dynamics of photosynthetic function within green foliage: the PRI is based on reflected radiation in the green spectrum associated with photoprotection via the xanthophyll cycle [2,6-9], whereas SIF [10] measures the absorbed photosynthetically active radiation discarded through emissions, rather than being utilized for photosynthesis. Our previous research demonstrates that the PRI displays directional responses that are strongly expressed and which can be related to the sunlit and shaded canopy fractions [6-9, 11-13]. Here, we examine the directional characteristics of red and far-red SIF and their ratio (red/far-red SIF ratio), and compare with those simultaneously acquired for the PRI, in a cornfield at two growth stages in 2010.

\section{METHODS}

In a USDA-ARS experimental field site located in Beltsville, MD, USA, canopy optical and biophysical measurements were acquired for a corn crop throughout the 2010 growing season, with the results from two growth stages are described here. Canopy passive optical measurements were made at nadir and for directional observations with a USB4000 Miniature Fiber Optic Spectrometer (Ocean Optics Inc., Dunedin, Florida, USA) at several times of day, to enable retrieval of SIF and PRI as a function view zenith angle $\left(\mathrm{VZA}, \theta_{\mathrm{V}}\right)$ and relative azimuth angle (RAA, $\psi$ ) at different times of day. The PRI is a normalized difference index (computed as the difference divided the sum) for reflectance measured at $531 \mathrm{~nm}$ and $570 \mathrm{~nm}$ [3]. SIF was determined from retrievals in the atmospheric oxygen absorption features centered at 688 and $760 \mathrm{~nm}$ using a modified Fraunhofer Line Depth (FLD) method [5]. 

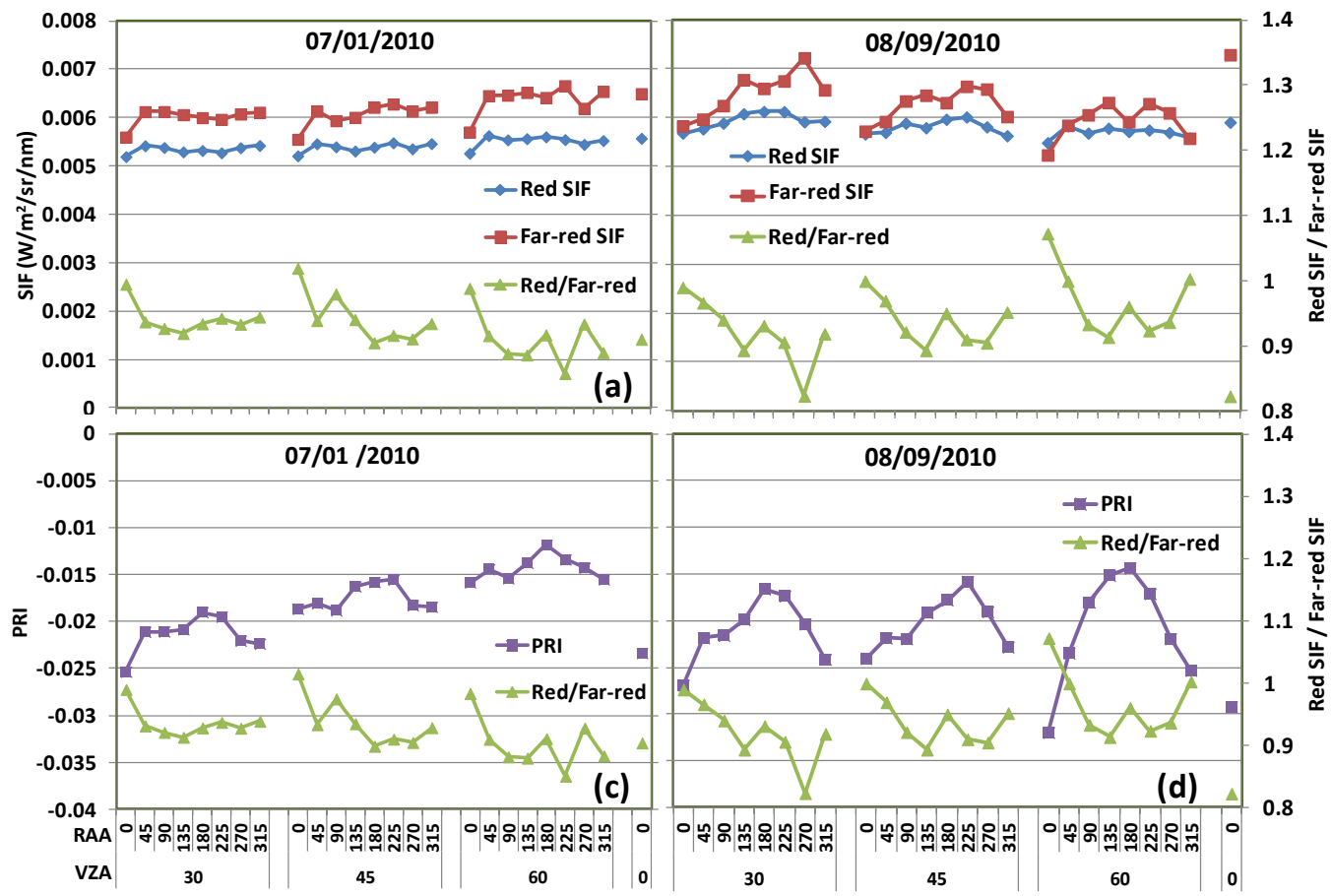

Figure 1. The daily average values for the red and far-red $\operatorname{SIF}(a, b)$, their ratio $(a, b, c, d)$, and the PRI $(c, d)$ obtained at four view zenith angles $\left(V Z A=0^{\circ}, 30^{\circ}, 45^{\circ}, 60^{\circ}\right)$ with eight relative azimuth angles $\left(R A A=0^{\circ}, 45^{\circ}, 90^{\circ}, 135^{\circ}, 180^{\circ}, 225^{\circ}, 270^{\circ}\right.$, $315^{\circ}$ ) on two field days in 2010 -- July 1(left) and August 9 (right). Y axes are: F(W/m $\left.{ }^{2} / \mathrm{sr} / \mathrm{nm}\right)$ and PRI (left side) and SIF ratio(right side).

\section{RESULTS}

We examined the SIF measured in situ with various directional viewing configurations on two contrasting days during the 2010 growing season that represent early (July 1) vs. late (Aug. 9) vegetative canopy conditions for the cornfield. The young canopy on July 1 , comprised entirely of healthy, green foliage at $\sim 1 \mathrm{~m}$ height, was actively growing and relatively unstressed. One month later in August, the lower canopy had begun to senesce after the mature canopy had attained full height $(\sim 2 \mathrm{~m})$ and entered the early senescent stage (R3). Daily averages for canopy remote sensing observations [Fig. 1] acquired in complete $360 \mathrm{o}$ azimuth sweeps at three VZAs $\left(\theta_{\mathrm{V}}=30^{\circ}, 45^{\circ}, 60^{\circ}\right)$ differed significantly: (a) for the SIF at the two growth stages, and (b) for SIF vs. PRI at both growth stages. For the young crop, SIF in the red band [Fig. 1a] was relatively constant at $\sim 0.0055 \pm 0.0025 \mathrm{~W} / \mathrm{m}^{2} / \mathrm{sr} / \mathrm{nm}$ at all viewing conditions $\left(3 \theta_{\mathrm{V}}, 8 \psi\right)$ whereas far-red SIF was slightly higher and increased for $\theta_{\mathrm{V}} 30^{\circ} \rightarrow 60^{\circ} \quad(0.0055-0.0067$ $\mathrm{W} / \mathrm{m}^{2} / \mathrm{sr} / \mathrm{nm}$ ).

SIF in both bands was greater in the mature canopy [Fig. 1b] where average SIF decreased for $\theta_{\mathrm{V}} 30^{\circ} \rightarrow 60^{\circ}$. But, the red SIF at this stage remained relatively insensitive to RAA differences, declining only slightly at the oblique $\theta_{\mathrm{V}}$ $=60^{\circ}\left(\sim 0.0061\right.$ to $\left.0.0058 \mathrm{~W} / \mathrm{m}^{2} / \mathrm{sr} / \mathrm{nm}\right)$. However, the average far-red SIF exhibited a significant decrease (from
0.0065 to $0.006 \mathrm{~W} / \mathrm{m}^{2} / \mathrm{sr} / \mathrm{nm}$ ) at oblique $\theta_{\mathrm{V}}$, and significant variation with $\psi$. The highest far-red SIF in the mature canopy was obtained at smaller $\theta_{\mathrm{V}}$ (nadir, $30^{\circ}$ ) and near the "coldspot" associated with shaded foliage at each $\theta_{\mathrm{v}}$. These responses affected the red/far-red SIF ratios: the largest ratio values were obtained for the "hotspot" $\left(\psi=0^{\circ}\right)$ at both growth stages. This ratio was lower $(\sim 0.88 \pm 0.4)$ in early July, indicating relatively more red than far-red SIF was emitted from the canopy, than in August when the ratio approached equivalence (near $\sim$ ) [Fig. $1 \mathrm{a}, \mathrm{b}$ ] but varied greatly among azimuth positions at each $\theta_{\mathrm{V}}(0.83-1.07)$ and, most important, was highest for any $\theta_{\mathrm{V}}$ at the hotspot. In concert, the PRI exhibited stronger directional responses than the SIF ratio, and showed consistent patterns with RAA variations, where for both growth stages the higher PRI values retrieved at any $\theta_{\mathrm{V}}$ were associated with the coldspot [Fig. $1 \mathrm{c}, \mathrm{d}]$. The average PRI increased with $\theta_{\mathrm{V}}$ in the young "unstressed" crop, but was more influenced by azimuth position in the mature crop. Clearly, the directional trends for the PRI and the SIF ratio exhibit inverse patterns [Fig. $1 \mathrm{c}, \mathrm{d}]$.

The daily averages $(\mathrm{X} \pm \mathrm{SE})$ are summarized for these results [Fig. 2] along the solar principal plane for the hotspot (RAA $=0^{\circ}$, orange bars) and the coldspot $\left(\mathrm{RAA}=180^{\circ}\right.$, purple bars); nadir values (green bars) are included for comparison. For the young canopy, daily averaged red SIF was equal for hotspot vs. coldspot vs. nadir, at each $\theta_{\mathrm{V}}$ [Fig. 
2a]. A similar pattern in the mature canopy was obtained at the hotspot, coldspot, and nadir viewing positions for red SIF, but values were somewhat higher and more variable [Fig. 2b]. However, the SIF ratio exhibited higher values at the hotspot at both growth stages, a trend that continued and was more strongly expressed in the mature canopy where a significantly lower SIF ratio was obtained at nadir [Fig. 2c,d]. In contrast to the SIF ratio, the PRI in the mature crop was significantly higher for the coldspot at each $\theta_{\mathrm{V}}$, as compared to either the hotspot or nadir [Fig. 2f]. A similar but less well developed PRI pattern occurred in the young crop [Fig. 2e].

A better understanding is gained by examining the morning vs. afternoon observations [Fig. 3]. Here, the bar chart provides the hotspots as orange (AM) or brown (PM), the coldspots as purple (AM) or navy (PM), and nadir as either light green (AM) or dark green (PM). Clearly, lower red SIF was obtained in AM vs. PM in the young canopy [Fig. 3a]. By Aug. 9, the red SIF in the morning had increased and was more variable [Fig. 3b]. The SIF ratio was higher in the hotspots vs. coldspots during mornings (both dates, Fig. 3 c,d), a trend that was more pronounced in the mature stage when the nadir values (AM, PM) were lowest. The PRI values in the mature crop were noticeably lower for any pair (e.g., hotspot at $\theta_{\mathrm{V}}=30^{\circ}$ ) for morning vs. afternoon [Fig. 3f]. Moreover, higher PRI values in the coldspot than the hotspot were observed for all examples in the mature growth stage [Fig. 3f], a trend that was also apparent but not significant in the young crop [Fig. 3e].

\section{SUMMARY}

Two spectral indices (PRI, SIF ratio) provided complementary information on the photosynthetic function of a corn canopy in 2010 at early vegetative and reproductive growth stages. More research is needed to understand the interrelationship of the PRI, SIF and photosynthetic function using remote sensing observations.

\section{REFERENCES}

[1] Beer, C., M. Reichstein, E. Tomelleri, P. Ciais, M. Jung, N. Carvalhais, C. Rodenbeck, M. A. Arain, D. Baaldocchi, G. B. Bonan, A. Bondeau, A. Cescatti, G. Lasslop, A. Lindroth, M. Lomas, S. Luyssaert, H. Margolis, K. W. Oleson, O. Roupsard, E. Veenendaal, N. Viovy, C. Williams, F. I. Woodward, and D. Papale, "Terrestrial gross carbon dioxide uptake: Global distribution and covariation with climate," Science, vol. 329, pp. 834-838, 2010.

[2] Middleton, E.M., K. F. Huemmrich, Y.-B. Cheng, and H. A. Margolis, "Spectral bioindicators of photosynthetic efficiency and vegetation stress," in Hyperspectral Remote Sensing of
Vegetation, P. S. Thenkabail, J. G. Lyon, and A. Huete, Eds., CRC Press, pp. 265-288, 2011.

[3] Gamon, J.A, C.B. Field, W. Bilger, O. Björkman, A. L. Fredeen, and J. Peñuelas, "Remote sensing of the xanthophyll cycle and chlorophyll fluorescence in sunflower leaves and canopies," Oecologia, vol. 85, pp. 1-7, 1990.

[4] Meroni, M., M. Rossini, L. Guanter, L. Alonso, U. Rascher, R. Colombo, and J. Moreno, "Remote sensing of solar-induced chlorophyll fluorescence: Review of methods and applications," Rem. Sensing of Environ., vol. 113, pp. 2037 2051, 2009.

[5] Maier, S.W., K. P. Günther, and M. Stellmes, "Sun-induced fluorescence: A new tool for precision farming," in Digital imaging and spectral techniques: Applications to precision agriculture and crop physiology, T. Van Toai, D. Major, M. McDonald, J. Schepers, and L. Tarpley, Eds., American Society of Agronomy, pp. 209-222, 2003.

[6] Middleton, E.M., Y.-B. Cheng, T. Hilker, T.A. Black, P. Krishnan, N.C. Coops, and K.F. Huemmrich (2009), "Linking foliage spectral responses to canopy level ecosystem photosynthetic light use efficiency at a Douglas-fir forest in Canada", Canadian J. Rem. Sens., vol. 35, pp. 166-188, 2009.

[7] Hilker, T., N. C. Coops, M. A. Wulder, T. A. Black, and R. D. Guy, "The use of remote sensing in light use efficiency based models of gross primary production: A review of current status and future requirements," Science of The Total Environment, vol. 404, pp. 411-423, 2008.

[8] Hilker, T., N. C. Coops, F. G. Hall, C. J. Nichol, A. Lyapustin, T. A. Black, M. A. Wulder, R. Leuning, A. Barr, D. Y. Hollinger, B. Munger, and C. J. Tucker, "Inferring terrestrial photosynthetic light use efficiency of temperate ecosystems from space," J. Geophys. Res., vol. 116, p. G03014, 2011.

[9] Cheng, Y.-B., Middleton, E.M., Hilker, T., Coops, N.C., Krishnan, P., \& Black, T.A. "Dynamics of Spectral Bioindicators and Their Correlations with Light Use Efficiency Using Directional Observations at a Douglas-fir Forest", Measurement Science and Technology, vol. 20, 15 pp., 2009.

[10] Middleton, E.M., Y.-B. Cheng, L. Corp, K. F. Huemmrich, W. Kustas, and P. K. E. Campbell, "Diurnal and Directional Responses of Chlorophyll Fluorescence and the PRI in a Cornfield," the 4th International Workshop on Remote Sensing of Vegetation Fluorescence, Valencia, Spain, 15-17 November, 2010.

[11] Cheng, Y.-B., E. M. Middleton, Q. Zhang, L. A. Corp, A. L. Russ, J. Dandois, and W.P. Kustas, "Utilizing in situ Directional Hyperspectral Measurements to Validate BioIndicators for a Corn Crop Canopy," Ecological Informatics, vol. 5, pp. 330-338, 2010.

[12] Cheng, Y.-B., E.M. Middleton, K.F. Huemmrich, Q. Zhang, L.A. Corp, P. Campbell, and W. Kustas, "Spectral Bioindicator Simulations for Tracking Photosynthetic Activities in a Corn Field," In, SPIE Optics and Photonics, San Diego, CA, USA, 2011.

[13] Cheng, Y.-B., E.M. Middleton, Q. Zhang, L.A. Corp, A.L. Russ, J. Dandois, and W.P. Kustas, W. P., "The Photochemical reflectance index from directional cornfield reflectances: Observations and simulations", submitted to Rem. Sensing of Environ., Nov. 2011. 


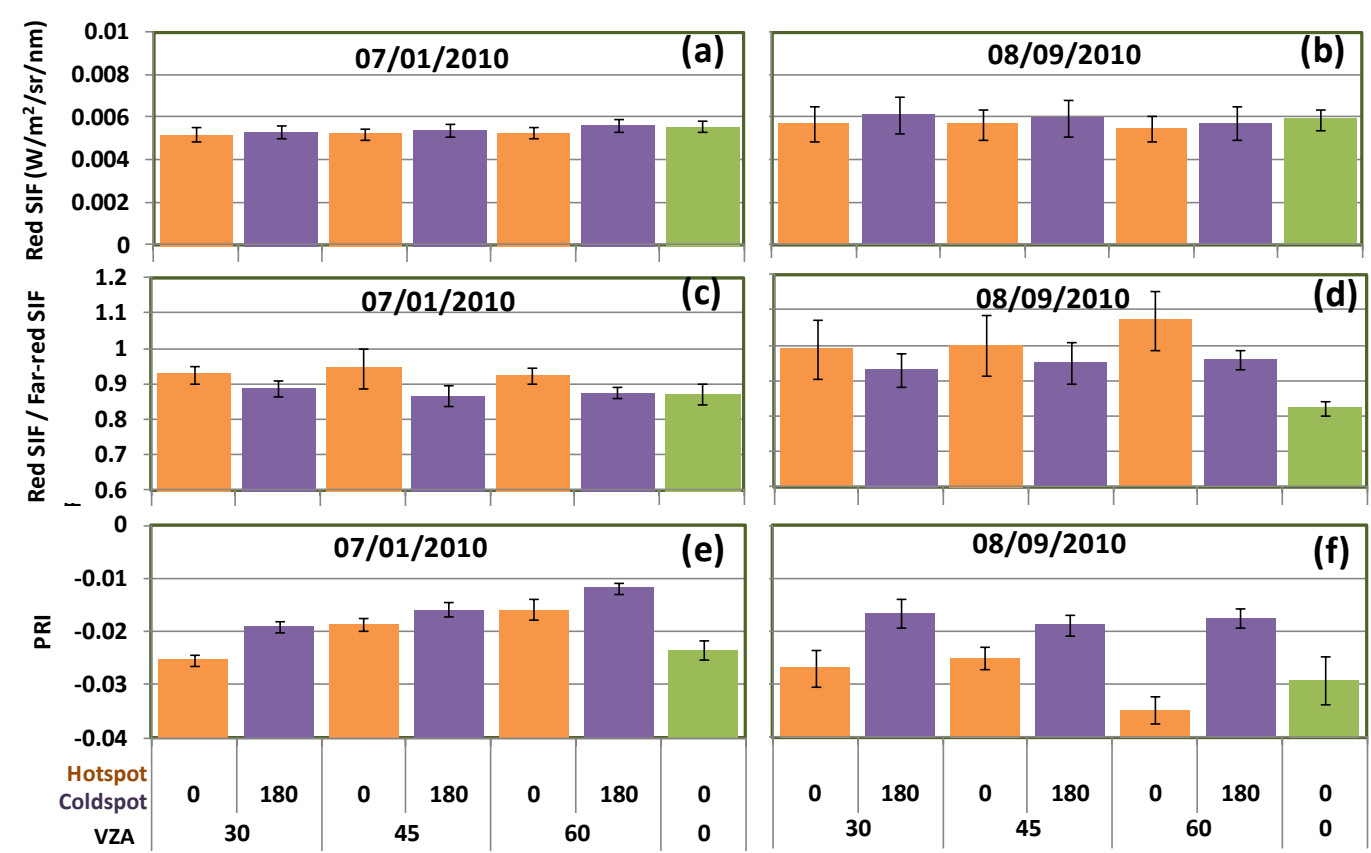

Figure 2. The daily average values (mean $\pm S E)$ for the hotspot $\left(R A A=0^{\circ}\right.$; orange bars), coldspot $\left(R A A=180^{\circ}\right.$, purple bars), and nadir (RAA $=O^{\circ}$, green bars) along the solar principal plane were extracted from the full azimuth polar set, obtained at four VZAs $\left(0^{\circ}, 30^{\circ}, 45^{\circ}, 60^{\circ}\right)$ on July 1 (a,c,e on left) and August 9 (b,d,fon right) in 2010.

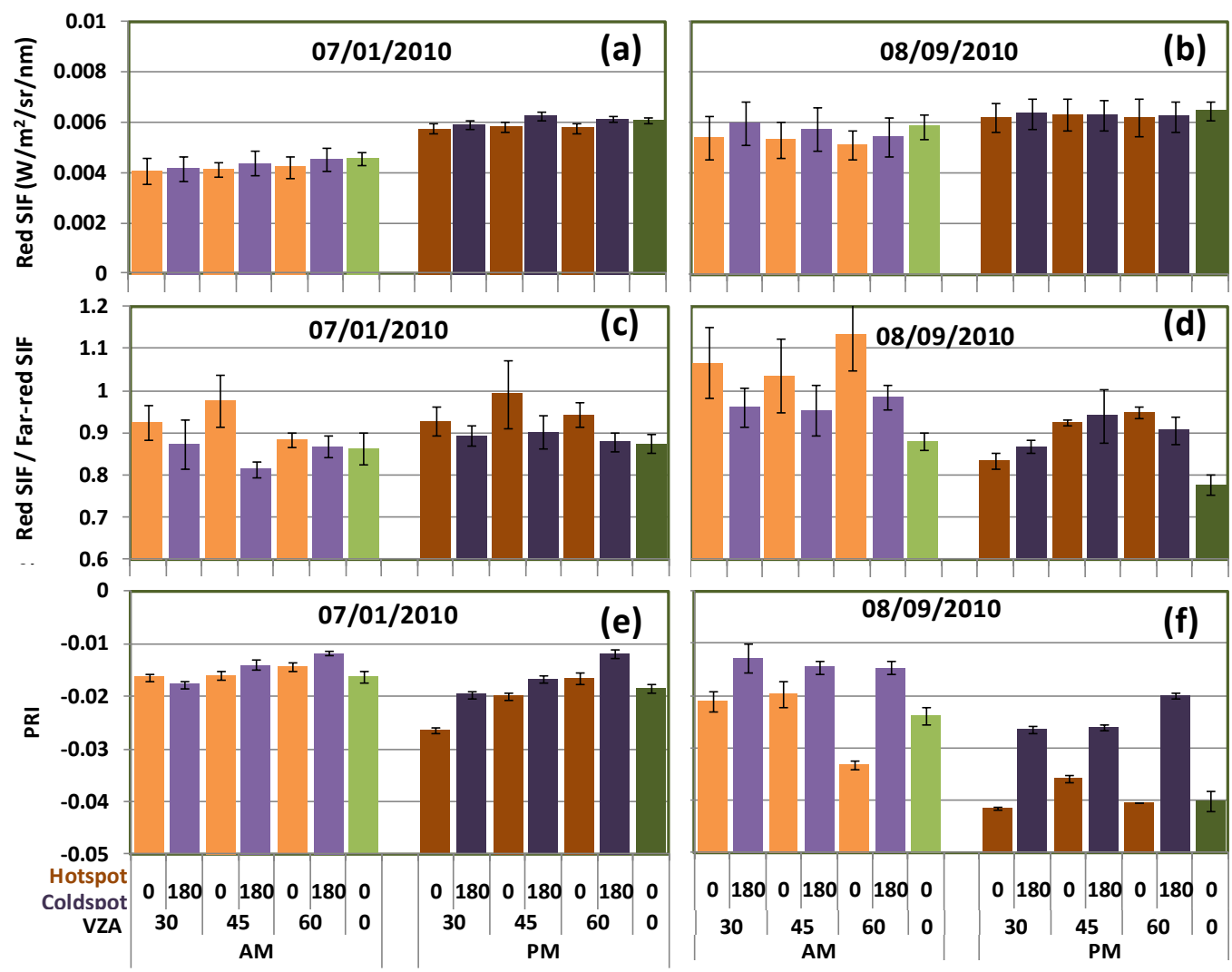

Figure 3. The average morning $(A M)$ and afternoon $(P M)$ values for three variables are shown: red SIF, top row; SIF ratio, middle row; PRI, bottom row. Results are for the hotspot (orange or brown bars; mean \pm SE), coldspot (purple or navy bars), and nadir (light green or dark green bars) along the solar principal plane were extracted from the full azimuth polar set, obtained at four VZAs $\left(0^{\circ}, 30^{\circ}, 45^{\circ}, 60^{\circ}\right)$ on July 1 (a,c,e on left) and August 9 (b,d,fon right) in 2010. 